\title{
The Effect of Innovativeness on Different Levels of Technology Adoption
}

\author{
Frank J. van Rijnsoever \\ Faculty of Geosciences, Innovation Studies Utrecht, Utrecht University, P.O. Box 80115, 3508 TC Utrecht, \\ The Netherlands. E-mail: F.vanrijnsoever@geo.uu.nl \\ A. Rogier T. Donders \\ Department of Epidemiology, Biostatistics and Health Technology Assessment, Radboud University Nijmegen \\ Medical Centre, P.O. Box 9101, 6500 HB Nijmegen, The Netherlands. E-mail: R.Donders@epib.umen.nl
}

\begin{abstract}
In this article, we look at the personality characteristic "global innovativeness" as a predictor for the adoption of consumer electronics; the latter being termed "actualized innovativeness." Global innovativeness is tested as a predictor for three levels of actualized innovativeness: at the domain-specific, cluster-specific, and productspecific levels. Our theoretical propositions are tested using two different surveys, one consisting of adolescent bachelor students $(n=138)$ and the second consisting of a heterogeneous broad sample $(n=450)$. The results of these studies show that the higher the level of abstraction of actualized innovativeness, the stronger the effects of global innovativeness. The implications of these findings are discussed.
\end{abstract}

\section{Introduction}

In consumer research, the concept of innovativeness has been defined and analyzed at multiple levels (Garcia \& Calantone, 2002), ranging from a personality trait to the result of actual (purchasing) behavior. Midgley and Dowling (1978) defined innovativeness as the degree to which an individual is receptive to new ideas and makes decisions on innovations independent of the communicated experience of others. Hirschman (1980) defined innovativeness as a type of inherent novelty-seeking attitude whereas Rogers (2003) used it as a concrete measure for the adoption of new products. Steenkamp, ter Hofstede, and Wedel (1999) adopted an intermediate position by stating that innovativeness is the tendency to be attracted by new products.

Three different levels of innovativeness are usually distinguished in the literature (Goldsmith, Freiden, \& Eastman,

Received February 15, 2008; revised December 8, 2008; accepted December 8,2008

(C) 2009 ASIS\&T • Published online 6 February 2009 in Wiley InterScience (www.interscience.wiley.com). DOI: 10.1002/asi.21029
1995; Mudd, 1990; Roehrich, 2004): global innovativeness as a personality trait; domain-specific innovativeness, which refers to the adoption of new items within a category of products; and product-specific innovativeness, which refers to the adoption of a single product. The latter two reflect the actual displayed innovative behavior (or actualized innovativeness) whereas the first level considers innovativeness as a personality trait. Another potential analysis level that has received much less attention in research is that of technology clusters (Larose \& Atkin, 1992; Rogers, 2003; Vishwanath \& Chen, 2006). Innovations that are often perceived to be related also have a higher likelihood of being adopted in combination with each other. These perceived-to-be-related innovations are called technology clusters. According to Van Rijnsoever and Castaldi (2009), technology clusters can be viewed as an intermediary level between the domain- and product-specific levels.

Past research has shown that global innovativeness represents those personality aspects that can be predictive for actualized innovativeness. Foxall (1994) found effects of global innovativeness on actualized innovativeness in some categories of products, but not in others. Im, Bayus, and Mason (2003) found that global innovativeness is directly related to the adoption of innovations within a product domain. Vishwanath (2005) reported that the effect of global innovativeness on cluster-specific innovativeness is mediated by media use and information-search strategies. These studies relate global innovativeness to a specific level of actualized innovativeness, but the effect of global innovativeness has never been tested at all three levels of actualized innovativeness.

The first contribution of this article is that it tests the effects of global innovativeness at the three different levels of actualized innovative behavior. In general behavioral terms, the relationship between personality traits and specific behaviors has been very difficult to illustrate empirically 
(Ajzen, 1988, 2005) because there are many confounding situational influences. The more specific the behavior is, the larger the chances of confounding influences on the behavior. We provide evidence for the proposition that global innovativeness predicts domain-specific innovativeness better than it does cluster- or product-specific innovativeness. Cluster-specific innovativeness, in turn, is better predicted than is product-specific innovativeness by global innovativeness. This study thus helps future scholars who study actualized innovativeness in choosing an appropriate level of analysis.

The second aim of this article is to test the relationships between global innovativeness and the two different measures of actualized domain-specific innovative behavior. It is subsequently argued that different measures are suitable for analyzing the actualized innovative behavior of different samples.

Finally, the results from this study show how global innovativeness, attitudinal constructs, and demographic characteristics are related to the measures of actualized innovativeness. We show that the effects of global innovativeness are relatively independent of the effects of demographics and attitudinal constructs.

Past research has established that actualized innovativeness is mostly limited to a single product domain (Rogers, 2003). People tend to be innovative within a product domain rather than among various domains. Consequently, we limit ourselves to the domain of consumer electronics-electronic products intended for everyday use by consumers. This study presents the results of two studies within this product domain. These studies provide support for the effects of global innovativeness at the various levels of actualized innovativeness. The first study concerns the adoption of information-technology objects, in relation to global innovativeness and attitudinal constructs, by a homogenous sample of undergraduate students. The second study concerns the time of adoption of three accepted information technology products: mobile telephones, computers, and the Internet. These innovations are related to global innovativeness and demographic variables in a broad sample of consumers.

\section{Theoretical Framework}

This section presents our research model. First, we discuss the dependent variables: product-specific, cluster-specific, and domain-specific innovativeness. Subsequently, the effect of global innovativeness on the dependent variables is considered. Next, we discuss the effects of the additional variables considered in the separate studies. The additional variables considered are the attitudinal constructs commonly associated with actualized innovativeness, such as leadership (Flynn, Goldsmith, \& Eastman, 1996; Summers, 1970) and trendiness (a type of involvement) (Chryssochoidis \& Wong, 2000; Dickerson \& Gentry, 1983). We also include demographics that are often used in the adoption literature (Dickerson \& Gentry, 1983; Im et al., 2003). Off course, many other variables are related to actualized innovativeness. In this article, we have chosen to exclude other actual displayed behaviors such as media use or personal contacts and only concentrate on actualized innovativeness.

\section{Levels of Actualized Innovativeness}

Actualized innovativeness is the relative time of adoption of an innovation (Midgley \& Dowling, 1978; Rogers, 2003). It thus reflects actual displayed behavior, which makes it a more objective method of conceptualizing innovativeness than are self-designated scales, such as those proposed by Goldsmith and Hofacker (1991) and Flynn et al. (1996), which are more sensitive to common method biases (Podsakoff, MacKenzie, Lee, \& Podsakoff, 2003).

Our dependent variables are the three levels of actualized innovativeness: domain-, cluster-, and product-specific innovativeness. Product-specific innovativeness is defined as the actual purchasing behavior of an individual of a specific new product. Domain-specific innovativeness is not the adoption of a specific product but rather the degree of product adoption within a product domain or category. Domain-specific innovativeness is the aggregate of the various purchased products, which are used to measure product-specific innovativeness. It thus reflects the adoptive behavior throughout an entire product domain rather than being related to only a single product. For both these levels, the same theoretical arguments are applicable, but we expect them to be stronger at the domainspecific level than at the product-specific level because the effects of personality traits are better visualized by aggregating a series of behaviors rather than by investigation of a specific behavior (Ajzen, 2005).

Within a product domain, various technology clusters can be distinguished. These products have a larger chance of being adopted simultaneously (Rogers, 2003; Vishwanath \& Chen, 2006). This becomes more probable if the innovation is perceived to be closely functionally related to other innovations (Larose \& Atkin, 1988; Van Rijnsoever \& Castaldi, (2009); Vishwanath \& Chen, 2006). For example, Leung (1998) found a significant influence of technologyclustering with reference to mobile-telephone ownership. Furthermore, Vishwanath and Goldhaber (2003) found that cellular-telephone ownership is predicted well by computer ownership.

When the relationship between innovations is very close in terms of functionality, the chances of adopting both technologies simultaneously can decrease because it is not very useful to buy two different items with exactly the same function (Van Rijnsoever \& Castaldi, 2009). The cluster-specific level thus indicates the products that are related in ownership within a product domain.

If the products within technology clusters are indeed adopted together, then the cluster-specific level should represent an intermediary analysis level that could be more accurate than the domain-specific level. This is because the adoption of products from different clusters within a domain might be determined different factors whereas the adoption of products from within the same cluster is influenced by the same factors. 


\section{Global Innovativeness}

Across the years, researchers have consistently found that the personality of an individual can be explained by five factors (Ajzen, 2005; Feist, 1998; John \& Srivastava, 1999; McCrae \& John, 1992) known as the "Big-Five." These factors are Extraversion, Agreeability, Conscientiousness, Emotional Stability/Neuroticism, and Originality. Extraversion and Originality are the two factors that are most related to seeking new ideas and experiences, and hence, innovativeness can be construed as a combination of these two factors (Kwang \& Rodrigues, 2002).

One prominent theory, proposed by Kirton (1976), describes global innovativeness by using a spectrum between adaption and innovation. In the problem-solving process, people try to either improve on existing solutions (adaption) or find new solutions (innovation) (Kirton, 1994). Adaptive individuals are known to be precise and reliable, to think within the existing frameworks, and prefer to work with well-established procedures. Innovators, on the contrary, are observed to be less focused on details and less reliable, but they propose more radical perspectives and are more inclined to challenge established rules and authority (Kirton, 1976, 1994). Furthermore, innovators are willing to accept more risks than are adaptors (Kirton, 1994). The less a product has diffused among its potential buyers, the more probable it is to be perceived as new and the more probable that it differs from previous choices and existing norms; therefore, early adoption of innovation entails more risk (Boyd \& Richerson, 1985).

Because early adoption involves more risk, innovative individuals are more inclined to be the earliest adopters of new items than are adaptive individuals. Adaptors, on the contrary, are more liable to remain loyal to their existing products until ownership of the new product is an established norm.

\section{Leadership}

Opinion leaders act as role models in the process of technology diffusion (Richerson \& Boyd, 2005; Rogers, 2003); they have the degree of freedom to introduce new norms into a group (Homans, 1974). Other members of the group copy from the leader to comply with established norms related to leadership and to prevent any loss of rank (Homans, 1974) or in the hope of copying the traits that made the opinion leader successful, thereby improving their own chances of success (Fisher \& Price, 1992; Richerson \& Boyd, 2005). However, opinion leadership and leadership are not identical. According to Rogers (1983), opinion leadership is

the degree to which an individual is able to influence other individuals' attitudes or overt behaviour informally in a desired way with a relative frequency. It is a type of informal leadership, rather than a function of the individuals' formal position or status in the system. (p. 27)

They serve as a gate through which new innovations can be introduced into a population (Katz \& Lazarsfeld, 1964; Valente, 1995).
Leadership can be defined as "a process that includes influencing the task objectives and strategies of a group or organization to implement the strategies and achieve the objectives, influencing group maintenance and identification, and influencing the culture of the organization" (Yukl \& Van Fleet, 1992, p. 149). Rogers (1983) focused mainly on the informal aspects of leadership because these are the most relevant for the diffusion process of innovations. In our study, leadership will be treated as a characteristic perceived by an individual, unchained by any situational setting. Differences are expected between those individuals who perceive themselves to be leaders and those who do not. Moreover, leadership is expected to be positively related to domain-, cluster-, and product-specific innovativeness.

\section{Trendiness}

Trendiness is defined as the extent to which an individual perceives him- or herself to be involved in the latest (technological) trends. Trendiness can be considered as part of a lifestyle, in contrast to innovativeness which is a personality trait: People purchase new technologies to enhance their social identity (Leung, 1998). This trendiness is expected to have a positive influence on the adoption process of innovations (Boyd \& Mason, 1999; Chryssochoidis \& Wong, 2000; Foxall, 1994, 1995). In accordance with Rogers (1983), we expect that trendiness will have a positive influence on domain-, cluster-, and product-specific innovativeness.

\section{Socioeconomic Status}

The relationship between socioeconomic level and actualized innovativeness is straightforward and has been widely researched. The higher the education of an individual, the more resources he or she has to spend (Advokaat, Chruchten, Gouweleeuw, Schulte Nordholt, \& Weltens, 2005) and the more probable that a new innovation will be adopted by him or her (Boone, 1970; Brancheau \& Wetherbe, 1990; Chia, Li, Detenber, \& Lee, 2006; Dickerson \& Gentry, 1983; Van den Bulte, 2000; Yang, 2005). In his qualitative study on the relationship between social class and financial behavior, Henry (2005) found that highly educated young professionals are more inclined to experiment with new products, thus expanding their boundaries, whereas the less educated, young working class are busy in to consolidating their current financial situation and are therefore less likely to experiment with new products. These differences in attitudes may provide an explanation for the higher socioeconomic status being positively related to domain-, cluster-, and product-specific innovativeness.

\section{Place of Residence}

The diffusion of innovations also is a function of the distance and density of potential adopters (Tolnay, 1995; Wejnert, 2002). In several instances, innovations are initially available in densely populated areas such as cities, 
for several reasons. An innovation might require an underlying infrastructure (as has been the case for electricity or the mobile telephone and, more currently, broadband Internet). Deploying these infrastructures can be more advantageous in cities because there are more potential adopters per unit of infrastructure (Brown, 1975). Moreover, in the case of telecommunications, cities need to be more connected to each other than do the rural regions (Moss \& Townsend, 2000).

In more densely populated areas, people have more chances of exchanging ideas and information, thus increasing the probability for observable innovations to be adopted (Richerson \& Boyd, 2005). Innovations diffuse generally from large to small settlements (Farag, Weltevreden, van Rietbergen, Dijst, \& van Oort, 2006; Hägerstrand, 1967). Consequently, the number of inhabitants in the place of residence of an individual has been added as an additional variable.

\section{Age and Gender}

Various studies have explored the impact of the variables "age" and "gender" on the adoption of technologies (e.g., Chia et al., 2006; Dickerson \& Gentry, 1983; Leung \& Wei, 1999). The effect of age varies for different innovations. Chia et al. (2006) found a negative relationship between age and the intention of adopting the Internet. For the adoption of mobile telephones, Leung and Wei (1999) also found a negative relationship. On the contrary, Dickerson and Gentry (1983) found a positive relationship for the adoption of home computers, although their study is rather old. The difference between the results is probably a consequence of the lack of the required resources for young people to buy an (in those days) expensive computer. Regarding gender, men are more interested in new technology than are women (Mammes, 2004) and are therefore more inclined to adopt new technologies; however, this general statement may vary depending on the technology.

\section{Study 1: The Relationship Between Global Innovativeness and Different Levels of Actualized Innovativeness in a Student Sample}

\section{Sample and Data Collection}

Undergraduate students of a first-year researchmethodology class and students of a second-year bachelor course on innovation and organization theory were asked to fill in a questionnaire. The sample size was 138 respondents, varying in age between 19 and 28 years; among these, 112 were men and 26 were women.

\section{Measurement and Analysis}

The questionnaire contained items measuring global innovativeness using a translated adapted version of Kirton (1976), perceived leadership, and trendiness. The latter two scales used were developed by the authors. Two factor analyses showed unidimensional structures and acceptable Cronbach's alpha indices (The exact items and the results of the factor analyses are presented in Appendix A.) Domainspecific innovativeness was measured by the "cross-sectional method" (Goldsmith \& Hofacker, 1991; Im et al., 2003; Midgley \& Dowling, 1978). The questionnaire inquired about the ownership of eight different products at the time of the survey. Each product was measured as a dummy (0/1) variable. This measure is appropriate because of the relatively young age of the respondents in the sample; measuring the number of years the respondents owned a certain item would be inaccurate because certain items are only purchased above a certain age. In addition, parental interventions and influences would affect the results (Cotte \& Wood, 2004). The products were selected so that they would be both affordable and remain within the range of interest of the respondents. Because all students were roughly of the same age and in the same phase of life, they had approximately the same purchasing power.

To measure cluster-specific innovativeness, the clusters in ownership were first determined. This was accomplished by extending the method proposed by Van Rijnsoever and Castaldi (2009). They provided an asymmetric association measure for binary variables, which operates as follows: Consider the following simple $2 \times 2$ matrix, in which the cell " $\mathrm{d}$ " represents the combined ownership of two technologies.

\begin{tabular}{l|c|c|}
\multicolumn{1}{c}{} & \multicolumn{1}{c}{0} & 1 \\
\multicolumn{1}{c}{} & $\left(\mathrm{C}_{0}\right)$ & $\left(\mathrm{C}_{1}\right)$ \\
\cline { 2 - 3 }$\left(\mathrm{R}_{0}\right)$ & $\mathrm{a}$ & $\mathrm{b}$ \\
\cline { 2 - 3 }$\left(\begin{array}{l}\left.\mathrm{R}_{1}\right) \\
\right.$\cline { 2 - 3 }\end{array} & $\mathrm{c}$ & $\mathrm{d}$ \\
\cline { 2 - 3 } & &
\end{tabular}

Van Rijnsoever and Castaldi (2009) used the following formula to associate pairs of combined ownerships:

$$
\text { match }=\frac{d-\min d}{\max d-\min d}
$$

where match is the matching coefficient between 0 and 1 , $d$ is the value of cell " $\mathrm{d}$," "min $d$ " is the minimum value of cell "d," and "max $d$ " is the maximum value of cell "d." This method to determine clusters is preferred to other measures, such as the principal-component or a phi-coefficient analysis, for two reasons. First, it is an asymmetric measure, which means that it considers only the combined ownership of technologies, not the common absence of technologies. Second, it permits guaranteed matches (e.g., matches based on chance). Not considering these guaranteed matches has the consequence that widely diffused technologies always have a higher degree of association. If Product 1, for example, is owned by $80 \%$ of the population and Product 2 by $90 \%$, then by definition, $70 \%$ of the population owns both products. However, the measure by Van Rijnsoever and Castaldi (2009) considers only the pairs that are based on chance and does not calculate $p$ values.

Clusters in ownership are characterized by the fact that the technologies within the clusters are adopted more in combination with each other. The matching coefficient thus should significantly depart from the value expected based on chance. 
TABLE 1. The measurements and descriptive statistics of Study 1.

\begin{tabular}{|c|c|c|c|}
\hline Variables & Details & $M$ & $S D$ \\
\hline Adoption & No. of times a person answered "yes" is the final score. & 3.76 & 1.66 \\
\hline Global innovativeness & $\begin{array}{l}\text { Scale adapted from Kirton (1976) ranging between } 32-160 \text { points } \\
\quad \text { (Cronbach's } \alpha=0.693 \text { ) }\end{array}$ & 99.90 & 8.96 \\
\hline Leadership & $\begin{array}{l}\text { On a 5-point Likert scale, seven different items were presented on } \\
\text { leadership (Cronbach's } \alpha=0.848 \text { ). }\end{array}$ & 23.81 & 4.57 \\
\hline Trendiness & $\begin{array}{l}\text { On a 5-point Likert scale, five different items were presented } \\
\quad \text { (Cronbach's } \alpha=0.726) \text {. }\end{array}$ & 15.58 & 3.28 \\
\hline Age & Age of the respondent & 20.86 & 1.85 \\
\hline Gender & No. Male/female & $112 / 26$ & \\
\hline Mobile telephone with camera function & Ownership (no. yes/no) & $91 / 47$ & \\
\hline iPod & Ownership (no. yes/no) & $22 / 116$ & \\
\hline Desktop, $<3$ years old & Ownership (no. yes/no) & $89 / 49$ & \\
\hline Memory stick with MP3 function & Ownership (no. yes/no) & $81 / 57$ & \\
\hline Digital camera & Ownership (no. yes/no) & $62 / 72$ & \\
\hline Portable GPS & Ownership (no. yes/no) & $13 / 125$ & \\
\hline Notebook $\mathrm{PC},<3$ years old & Ownership (no. yes/no) & $41 / 138$ & \\
\hline DVD player & Ownership (no. yes/no) & $113 / 25$ & \\
\hline
\end{tabular}

Therefore, we test the matching coefficients obtained by calculation against the expected values using a $\chi^{2}$ test with 1 $d f$. This $\chi^{2}$ test, in turn, is corrected for the pairs that are not formed based on chance. The standard formula for calculating the $\chi^{2}$ is as follows:

$$
\chi^{2}=\Sigma \frac{(O-E)^{2}}{E}
$$

where $O$ is the observed values in cell " $\mathrm{d}$ " and $E$ is the expected values of cell "d."

The expected values for cell "d" can be calculated from the cross table. The pairs not based on chance are the minimum number of pairs formed $(\min d)$ ). Correcting for these pairs, the formula can be written as follows:

$$
\chi^{2}=\Sigma \frac{((O(d)-\min d)-(E(d)-\min d))^{2}}{(E(d)-\min d)}
$$

Because both $O$ and $E$ are corrected for the same number of pairs, the difference between them is not affected by "min $d . "$ The formula therefore can be simplified to:

$$
\chi^{2}=\Sigma \frac{(O(d)-E(d))^{2}}{(E(d)-\min d)}
$$

This is tested against a $\chi^{2}$ distribution with $1 d f$; the critical value for $p<.05$ is 3.84 .

The table presented earlier shows that there are three significant relationships, from which two clusters can be formed. The first cluster consists of a portable global positioning system (GPS), a Notebook computer less than 3 years old, and a digital camera. The second cluster consists of a digital video disc (DVD) player and a desktop computer less than 3 years old. However, both desktop and notebook computers essentially carry out the same functions. A further analysis shows that if the dummy variables for the Notebook and Desktop computers are added together and recoded again to a dummy variable (Values $>0$ become 1 again.), there is an even stronger relationship with the DVD player. ${ }^{1}$ Therefore, the Notebook computer also was included in the cluster. The dummy variables in both clusters were added to provide the variables for cluster-specific innovativeness. The first cluster consists of technologies that are relatively less widely adopted, compared to the technologies in the second cluster.

The operationalization of the variables and their descriptive statistics are presented in Table 1. A Pearson correlation showed no interdependencies among the variables; all correlations remained at an acceptable level (see Appendix B for the full correlation matrix). A multiple ordinary leastsquares (OLS) regression was used to analyze the variables describing domain-specific adoption. Cluster-specific innovativeness was analyzed using ordinal regression analysis (McCullagh, 1980; McCullagh \& Nelder, 1998). Eight binary logistic-regression models were fitted to estimate the probability of owning one of the independent technologies for product-specific innovativeness.

Each model was analyzed in two blocks. In the first block, only global innovativeness was entered. In the next step, leadership, trendiness, gender, and age were added. For the product-specific models a third block was added, containing the ownership of the other products. The performance of the linear-regression model is expressed as the adjusted $R^{2}$. For the ordinal and the binary logistic-regression models, the Nagelkerke $R^{2}$ was used as a pseudo $R^{2}$ measure.

\section{Results and Discussion}

Table 2 presents the results of the regression analyses. At the domain-specific level, the standardized residuals are distributed normally. In the first block, global innovativeness has

\footnotetext{
${ }^{1}$ All other relationships with products having overlapping functions also were explored, but no significant relationships were found.
} 


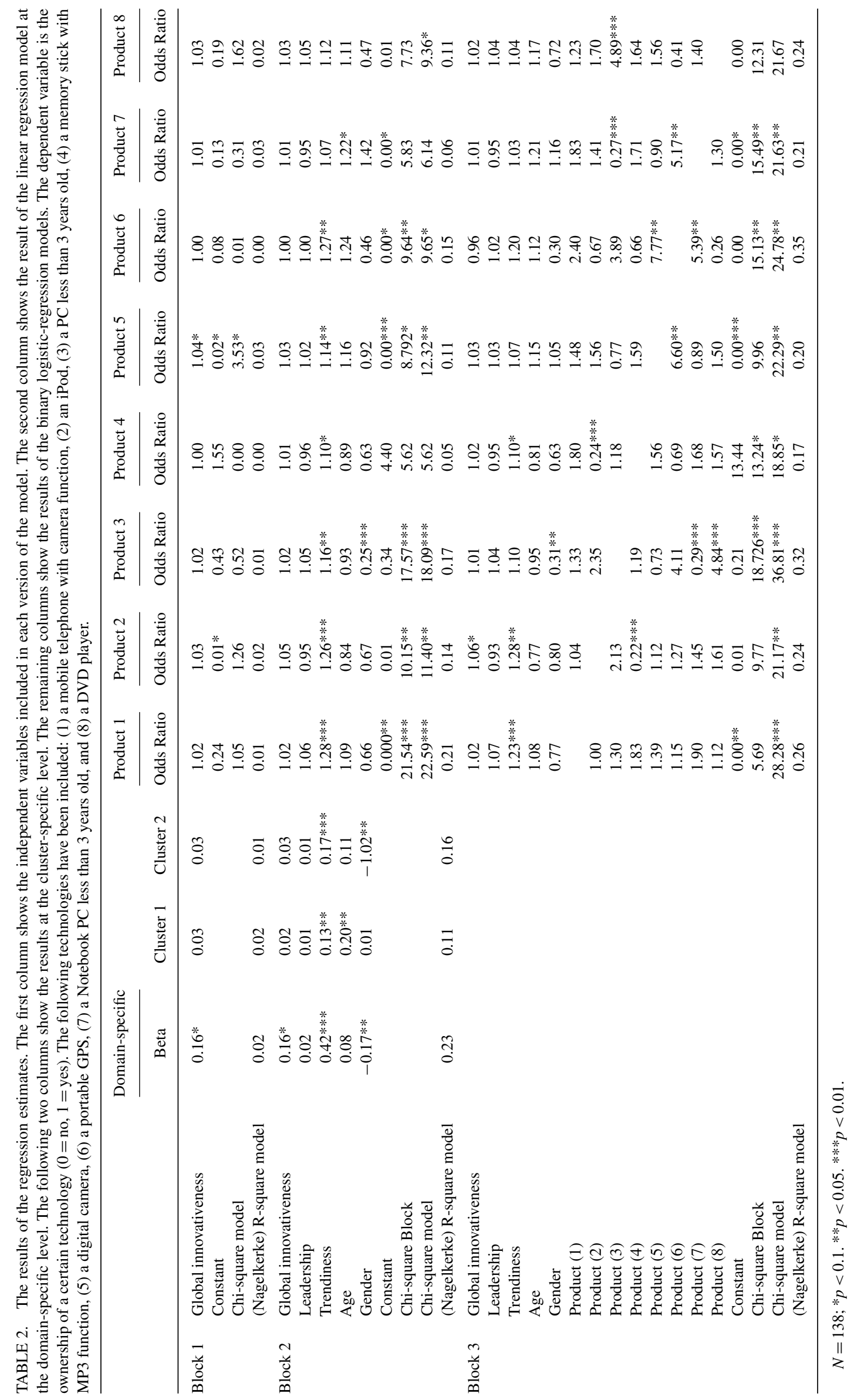


a significant (at the $10 \%$ level), but very limited, explanatory value (adjusted $R^{2}=0.017$ ). After the addition of the variables in Block 2, the adjusted $R^{2}$ becomes 0.232 , and global innovativeness remains significant at the $10 \%$ level. The largest contributions to the model are from trendiness and gender. Trendiness is a far better predictor than is global innovativeness in predicting the probability of adoption at a domain-specific level. Age has no influence on domainspecific adoption; this probably is due to the homogeneity of the respondents in the sample or because of the wide range of products included in the dependent variable. Finally, men are more inclined to adopt new technologies than are women. This is consistent with the findings of Mammes (2004), who claimed that males have more interest in technology than females.

On a cluster-specific level, global innovativeness does not have a significant effect on predicting both clusters. After the addition of the variables in Block 2, trendiness is significant in both instances. Age is positively related to Cluster 1 whereas men are more inclined to own products from Cluster 2. These two results would not have been found if the cluster-specific level was not analyzed. Thus, analyses at the cluster-specific level can show interesting results, but these clusters are perhaps too specific to measure the effects of a personality trait such as global innovativeness.

At a product-specific level, global innovativeness does not have a significant effect at the 5\% level. This finding is in accordance with that of Ajzen (2005) and Goldsmith et al. (1995). Surprisingly, leadership does not have any predictive value in any of the models. This result could be due to the homogeneity in the age of the sample or because this characteristic only begins to exert its effect at a later stage in life. The results imply that there is a difference between perceived leadership (by the individual) and opinion leadership. People who think of themselves as leaders do not necessarily determine norms in a group regarding technology by being the first to adopt new consumer electronics.

At a product-specific level, the mobile telephone with camera function, the iPod, and the portable GPS are best predicted by trendiness. The mobile telephone with camera function and the iPod can be considered to be trendy products: They have an additional brand label or functionality attached, which distinguishes them from other similar products. Trendiness for these two products is a better predictor than it is for the ordinary mobile telephone (Of 138 respondents, only 1 did not own a mobile telephone.) and the MP3 player. The portable GPS is the least diffused of all technologies and can hence be considered as the most innovative product and, therefore, trendy. The other products are generally less fashionable or trendy; therefore, there is a weaker, or even no relationship with trendiness.

Gender only plays a role in the ownership of a computer; apparently, in this sample, men are more interested in having a relatively new computer than are women.

There are limitations to this study. The sample used is a convenience sample; therefore, the results can be generalized to a limited extent only. The results from this study do, however, provide interesting insights about the levels at which actualized innovativeness can be analyzed and on the methodology for determining clusters.

\section{Conclusions of Study 1}

Due to the limitations of sampling method, we formulate our conclusions in such a manner that they are only about the sample that is being studied:

- In this study, global innovativeness is a better predictor for domain-specific innovativeness than it is for cluster- and product-specific innovativeness.

- In this study, the results indicate that trendiness is a better predictor for the adoption of new consumer electronics than global innovativeness at all three levels. Trendiness, however, is a very sample-specific measure.

- The results from this study indicate that the cluster-specific level can be a suitable level of analysis to show specific effects that would not have been found at the domain-specific level. The product-specific level, on the other hand, is probably too detailed a level of analysis from which to draw any general conclusions.

\section{Study 2: The Relationship Between Global and Actualized Innovativeness With Reference to Sociodemographic Characteristics}

\section{Sample and Data Collection}

Each of the 101 students of a first-year bachelor course on research methodology at a European university was asked to distribute a questionnaire to 6 individuals he or she knew. Two of these individuals were to be the parents of the students, if possible; 2 were to be brothers or sisters, if possible, and 2 other persons were to be from his or her social environment. If a person did not have a certain relative, a brother for example, he or she was obliged to substitute that relative with an individual from his or her own social environment. This resulted in a sample of 450 respondents (not all students did entirely complete the assignment). The sample consisted of 266 men and 184 women; age varied between 13 and 80 years. Because of the approach by which the questionnaires were distributed, the respondents were inclined to be young: Over $50 \%$ of them were younger than 30 years of age.

The method of sampling resulted in two distinct age groups in the sample. Therefore, the sample was split into two subsamples: one subsample containing all the respondents who were 27 years of age or younger $(n=271)$ and the second subsample with respondents older than 27 years $(n=179)$. The splitting of the sample into two groups allowed us to compare the results between the older and the younger age groups. This comparison will help us to address the applicability of the measure used for actualized innovativeness.

\section{Measurement and Analysis}

The respondents were provided with a questionnaire consisting of 52 items. These items were indicators for 
product-specific innovativeness, global innovativeness (using a translated, adapted version of Kirton, 1976, and demographic variables such as gender, age, socioeconomic level, and the number of inhabitants in the place of residence). Product-specific innovativeness was measured as the years of ownership of a mobile phone, a personal computer (PC), and Internet access - three technologies that have revolutionized our technique of communication and data processing over the past few decades.

These technologies were chosen because the heterogeneity of the sample limits the number of products that can be included. Individuals of different ages have different interests and occupations, which can lead to different times of adoption for different products (Midgley \& Dowling, 1978). Using a limited number of products, but adding the time of adoption of the technology, provides us with an adequate measure for product-specific innovativeness in this sample. Because the products were not measured as dummy variables but as continuous variables, we did not need to use the method by Van Rijnsoever and Castaldi (2009) to identify technology clusters. Instead, we followed Vishwanath (2005) and carried out a principal-component analysis, the extracted factors of which represent clusters. Only one factor was extracted, which implies that the domain- and cluster-specific levels are equal in the sample for this set of technologies. We refer to this result as the domain-specific level. The values of the productspecific variables were standardized and added to derive the domain-specific variable.

The measurement of the variables and their descriptive statistics are presented in Table 3 . We separately analyzed the total sample and the two subsamples. To check for interdependencies among the independent variables, we again conducted a Pearson correlation (see Appendix C): A strong, but acceptable (in terms of collinearity), significant correlation was found between age and socioeconomic status in the entire sample $(r=0.703, p<.001)$. For the total sample, four OLS-regression models were estimated, one for domain-specific innovation and three for product-specific innovation. Furthermore, for each of the two subsamples, an OLS-regression model was estimated at the domain-specific level. The analyses were carried out in multiple blocks. The first block contained global innovativeness as the only independent variable; in the second block, the other demographic variables were added. In the product-specific models, the other two technology variables were added as a third block. Multiple imputation was used to explain the missing values (Donders, van der Heijden, Stijnen, \& Moons, 2006), using the R-Program (R Development Core Team, 2007). This did not yield different results compared to the analysis without the imputation. The models without imputation will be presented herein because this allows us to present model-performance estimators.

\section{Results and Discussion}

Table 4 shows the results of the OLS-regression analyses. There is a significant positive relationship between

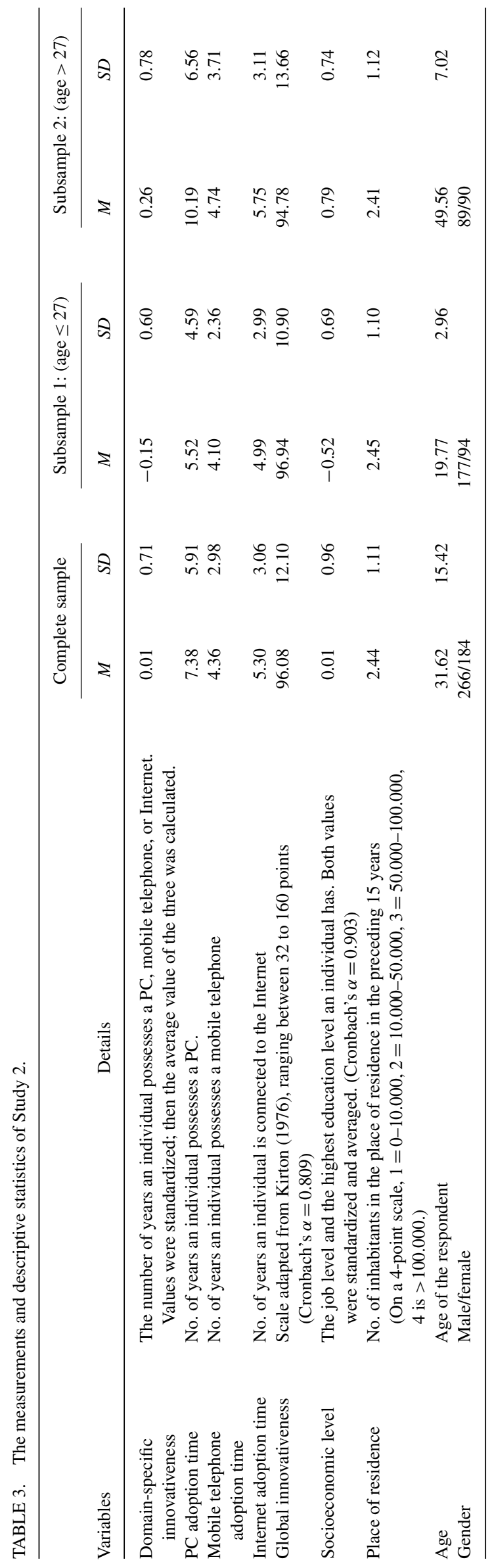


TABLE 4. The standardized estimates of the OLS regression analysis for the full sample. The columns represent the different dependent variables. The first column gives the names of the independent variables added in each step of the model. The second column gives the results for the domain specific level, the others give the results for the product specific models.

\begin{tabular}{|c|c|c|c|c|c|c|c|}
\hline & & $\begin{array}{c}\text { Domain- } \\
\text { specific } \\
\text { innovativeness }\end{array}$ & $\begin{array}{c}\text { Domain- } \\
\text { specific } \\
\text { innovativeness } \\
\text { Sub-sample 1: } \\
\text { age } \leq 27\end{array}$ & $\begin{array}{c}\text { Domain- } \\
\text { specific } \\
\text { innovativeness } \\
\text { Subsample 2: } \\
\text { age }>27\end{array}$ & $\begin{array}{c}\text { Product- } \\
\text { specific } \\
\text { innovativeness } \\
(\mathrm{PC})\end{array}$ & $\begin{array}{c}\text { Product- } \\
\text { specific } \\
\text { innovativeness } \\
\text { (Mobile } \\
\text { telephone) }\end{array}$ & $\begin{array}{c}\text { Product- } \\
\text { specific } \\
\text { innovativeness } \\
\text { (Internet) }\end{array}$ \\
\hline \multirow[t]{2}{*}{ Block 1} & Global innovativeness & $0.13 * * *$ & $0.10^{*}$ & $0.23 * * *$ & $0.81 *$ & 0.06 & $0.14 * * *$ \\
\hline & Adjusted R-square Block 1 & 0.02 & 0.01 & 0.05 & 0.00 & 0.00 & 0.02 \\
\hline \multirow[t]{6}{*}{ Block 2} & Global innovativeness & $0.13 * * *$ & $0.11^{*}$ & $0.13^{*}$ & $0.09 * *$ & 0.05 & $0.14 * * *$ \\
\hline & Socio-economic level & $0.27 * * *$ & 0.09 & $0.28 * * *$ & $0.20 * * *$ & $0.31 * * *$ & 0.08 \\
\hline & Place of residence & $-0.08 *$ & 0.01 & $-0.20 * * *$ & $-0.08^{*}$ & $-0.08 *$ & -0.01 \\
\hline & Age & $0.12 * *$ & 0.09 & -0.02 & $0.27 * * *$ & $-0.11 *$ & 0.10 \\
\hline & Sex & $-0.11 * *$ & -0.06 & $-0.15^{*}$ & $-0.08 *$ & $-0.09 *$ & -0.07 \\
\hline & Adjusted R-square Block 2 & 0.16 & 0.02 & 0.18 & 0.19 & 0.07 & 0.04 \\
\hline \multirow[t]{9}{*}{ Block 3} & Global innovativeness & & & & 0.04 & 0.03 & $0.11 * *$ \\
\hline & Socio-economic level & & & & $0.11 *$ & $0.25 * * *$ & 0.02 \\
\hline & Place of residence & & & & -0.05 & -0.06 & 0.01 \\
\hline & Age & & & & $0.26 * * *$ & $-0.18 * * *$ & -0.02 \\
\hline & Sex & & & & -0.03 & -0.07 & -0.05 \\
\hline & PC time of adoption & & & & & $0.31 * * *$ & $0.40 * * *$ \\
\hline & Mobile Phone time of adoption & & & & $0.24 * * *$ & & -0.07 \\
\hline & Internet time of adoption & & & & $0.31 * * *$ & -0.08 & \\
\hline & Adjusted R-square block 3 & & & & 0.34 & 0.13 & 0.16 \\
\hline
\end{tabular}

$N=450 ; * p<0.1 . * * p<0.05 . * * * p<0.01$

global innovativeness and domain-specific innovativeness. The addition of the other variables in the second block does not change the results related to global innovativeness.

However, for the three separate technologies, this is not always the case. Global innovativeness is not a significant predictor for the time of adoption of the mobile telephone, but it is for the PC and the Internet. There are a few explanations for these differences. An explanation can be found in the compatibility of the innovation with the user: The more radical the innovation, the less probable that it fits existing values and competences (Gatignon, Tushman, Smith, \& Anderson, 2002; Henderson \& Clark, 1990). Although the introduction of the mobile telephone significantly broadened the possibilities for communicating, using a mobile telephone was not a completely new method of communication but rather a substitution for or an addition to the traditional fixed telephone (Mahler \& Rogers, 1999; Sung \& Lee, 2002). The PC was a substitute for a number of devices (Utterback, 1996). With its various functions related to administration purposes, gaming, and the Internet, it broadened possibilities to a far larger extent (in the early years) than does the mobile telephone. A possible interpretation is that the $\mathrm{PC}$ was a more radical innovation than was the mobile telephone, making it more likely for people with a higher global innovativeness to adopt it. Another potential explanation is the dependence on a supporting infrastructure (Kaufman \& Techatassanasoontorn, 2005): Both mobile telephones and the Internet need a supporting infrastructure to operate. However, because global innovativeness influences the adoption of the Internet, but not that of the mobile telephone, it is improbable that this factor plays a role here.
Socioeconomic level explains a large part of domainspecific innovativeness in general and of the adoption of computers and mobile telephones in particular. The socioeconomic level does not contribute significantly in explaining adoption of the Internet. This may partly be explained by the fact that adoption of the Internet depends on the ownership of a PC. Furthermore, compared to the other two technologies, the Internet is relatively cheap to adopt.

Place of residence as a predictor for domain-specific innovativeness is significant at the $10 \%$ level. Contrary to our expectations, domain-specific innovativeness is slightly higher in the smaller communities than it is in the larger cities. This might be due to the fact that many high-income families live in suburbs rather than in large cities.

Gender and age are significant in the domain-specific model, but not always in the product-specific models. In general, there is a positive relationship between age and actualized innovativeness, although this may depend on the specific technology. Men, at the domain-specific level, also are quicker to adopt new technologies than are women, but this phenomenon is hardly reflected at the product-specific level.

The third block replicates the results of Vishwanath and Goldhaber (2003): Mobile-telephone ownership is predicted by computer ownership. Logically, there also is a strong relationship between computer ownership and Internet use.

When the results from the subsamples are compared, large differences are found. Global innovativeness has a strong, significant positive effect on domain-specific innovativeness in Subsample 2 whereas it is only significant at the $10 \%$ level in Subsample 1. Furthermore, none of the demographic variables are significant in Subsample 1 (age $\leq 27)$ whereas 
socioeconomic level and place of residence are highly significant in Subsample 2 (age $>27$ ). There are a number of possible explanations for these differences. First, the measure for domain-specific innovativeness is based on the number of years the products are owned. The relatively young age of the respondents in Subsample 1 limits the number of years the technologies can be owned by the respondents. Moreover, because of their age, the chances that these respondents were not actively involved in the purchasing process are larger. A cross-sectional measure, such as that in Study 1, could have been more appropriate for Subsample 1. Following the measure for the dependent variable, the homogeneity of the respondents in Subsample 1 is probably an additional reason for there being no effect of the demographic variables on domain-specific innovativeness. The respondents are roughly of the same age and predominantly have the same socioeconomic status.

In Subsample 2, the effects of socioeconomic status are predicted by our theoretical framework for the socioeconomic level, but not for the place of residence, which is strongly negatively related to domain-specific innovativeness. Again, this might be explained by the fact that many relatively highincome households live in suburbs rather than in the big cities.

The main limitation of this study is the method of sampling. Although this sample is broader and therefore more representative than the sample in the first study, it is still not an accurate representation of the population. This study, however, does show the differences in effects between the two groups when using the time of adoption as a measure for actualized innovativeness.

\section{Conclusions of Study 2}

Due to the limitations of sampling method, we formulate our conclusions in such a manner that they are only about the sample that is being studied:

- In this study, based on these three technologies, global innovativeness has an explanatory value for domain-specific innovativeness, next to and operating independently from demographic variables.

- For this sample, differences were found in the effects of global innovativeness at a product-specific level. The attributes of the different technologies can be helpful in explaining these differences.

- It has been established for this sample that measuring the time of adoption can be used as a measure for actualized innovativeness. The respondents in the sample, however, do have to be old enough for this measure to be applicable.

\section{General Discussion}

The results of the two studies complement each other. At a domain-specific level, the results of the first study also are partly found in the second study. In both studies, we found that the higher the aggregation level of the actualized innovativeness, the stronger the effects of the manifested global innovativeness. This finding is in accordance with previous claims by Ajzen (2005). Analyzing at the domain-specific level thus may visualize the effects of personality traits. The high level of abstraction, however, also masks other effects from variables that are more related to a specific product or technology cluster. In both studies, these types of effects were found. We therefore recommend that scholars conduct their future studies on actualized innovativeness at more than one level of aggregation. This does not have to be at the product-specific level, which can very rapidly lead to plenty of analyses with only a few usable results. The cluster-specific level can be a good alternative because the technologies in a cluster have a higher probability of being adopted together and are therefore more probable to be predicted by the same variables.

The studies also have shown the importance of choosing the right type of method for measuring actualized innovativeness. The cross-sectional method worked in the first study because of the homogeneity of the sample. In more heterogeneous samples, there probably would have been biases caused by other variables because finding products that are equally interesting for all respondents would have been much more difficult.

The use of time of adoption as a measure for actualized innovativeness provides more information than only measuring the ownership of a product. It also permits the products that are not innovative at the present to be still included in the measure, thus providing an image of actualized innovativeness throughout a longer period of time. A condition for using time of adoption as a measure is that all respondents should have had equal chances in the past to easily adopt the innovation. This measure is thus very susceptible to the influence of age or other time-related variables.

The different measures applicable for actualized innovativeness also imply use of different methods for finding technology clusters. When measuring the time of adoption, the variables are of a continuous nature; therefore, a factor analysis can be applied to identify clusters. The crosssectional method does not allow the use of a factor analysis. Methods such as those used in Study 1 of this article and in the report by Van Rijnsoever and Castaldi (2009) are usable alternatives.

Global innovativeness, by itself, remains a poor practical measure for directly explaining domain-, cluster-, or productspecific innovativeness. It is relatively distinct from other concepts in the various models used currently, which can warrant the use of global innovativeness in future models, but the effects of global innovativeness on actualized innovativeness were rather small. In our two studies, variables such as socioeconomic level and trendiness proved to be have a greater predictive value, but these also are very samplespecific measures. Interestingly, for Subsample 2 of Study 2, the effect of global innovativeness proved to be much stronger than that for Subsample 1. The age of the respondents thus plays a role in determining the potency of the influence of innovativeness.

Due to the sampling method used herein, it is difficult to generalize the results from both studies, but they provide 
interesting insights regarding the role of global innovativeness in the adoption processes of individuals. Therefore, we stress that these studies should be considered as pilot studies. Further research will have to be conducted to learn whether the insights found bear greater external validity.

\section{Acknowledgments}

The authors thank Henk van Peer for his advice and help with administering the questionnaires.

\section{References}

Advokaat, W., Chruchten, J. van, Gouweleeuw, J., Schulte Nordholt, E., \& Weltens, W. (2005). Loon naar beroep en opleidingsniveau: Het loonstructuur onderzoek 2002 [Salaries by occupation and education level: The wage structure study 2002]. Sociaal-economische trends (pp. 39-51). Heerlen, The Netherlands: CBS.

Ajzen, I. (1988). Attitudes, personality and behavior. Chicago: Dorsey Press. Ajzen, I. (2005). Attitudes, personality and behavior (2nd ed.). Berkshire, England: Open University Press.

Boone, L.E. (1970). The search for the consumer innovator. Journal of Business, 43, 135-140.

Boyd, R., \& Richerson, P.J. (1985). Culture and the evolutionary process. Chicago: University of Chicago Press.

Boyd, T.C., \& Mason, C.H. (1999). The link between attractiveness of "extrabrand" attributes and the adoption of innovations. Journal of the Academy of Marketing Science, 27(3), 306-319.

Brancheau, J.C., \& Wetherbe, J.C. (1990). The adoption of spreadsheet software: Testing innovation diffusion theory in the context of end-user computing. Information Systems Research, 1(2), 115-143.

Brown, L.A. (1975). The market and infrastructure context of adoption: A spatial perspective on the diffusion of innovation. Economic Geography, 51(3), 185-216.

Chia, S.C., Li, H., Detenber, B., \& Lee, W. (2006). Mining the internet plateau: An exploration of the adoption intention of non-users in Singapore. New Media \& Society, 8(4), 589-609.

Chryssochoidis, G.M., \& Wong, V. (2000). Customization of product technology and international new product success: Mediating effects of new product development and rollout timeliness. Journal of Product Innovation Management, 17(4), 268-285.

Cotte, J., \& Wood, S.L. (2004). Families and innovative consumer behavior: A triadic analysis of sibling and parental influence. Journal of Consumer Research, 31(1), 78-86.

Dickerson, M.D., \& Gentry, J.W. (1983). Characteristics of adopters and non-adopters of home computers. Journal of Consumer Research, 10(2), 225-235.

Donders, A.R.T., van der Heijden, G.J.M.G., Stijnen, T., \& Moons, K.G.M. (2006). Review: A gentle introduction to imputation of missing values Journal of Clinical Epidemiology, 59(10), 1087-1091.

Farag, S., Weltevreden, J., van Rietbergen, T., Dijst, M.T., \& van Oort, F. (2006). E-shopping in the Netherlands: Does geography matter? Environment and Planning B-Planning \& Design, 33(1), 59-74.

Feist, G.J. (1998). A meta-analysis of personality in scientific and artistic creativity. Personality and Social Psychology Review, 4(2), 290-309.

Fisher, R.J., \& Price, L.L. (1992). An investigation into the social-context of early adoption behavior. Journal of Consumer Research, 19(3), 477-486.

Flynn, L.R., Goldsmith, R.E., \& Eastman, J.K. (1996). Opinion leader and opinion seekers: Two new measurement scales. Journal of the Academy of Marketing Science, 24(2), 137-147.

Foxall, G.R. (1994). Consumer initiators: Both innovators and adaptors! In M.J. Kirton (Ed.), Adaptors and innovators: Styles of creativity and problem solving. (pp. 114-136). London: Routledge.

Foxall, G.R. (1995). Cognitive styles of consumer initiators. Technovation, 15(5), 269-288.
Garcia, R., \& Calantone, R. (2002). A critical look at technological innovation typology and innovativeness terminology: A literature review. Journal of Product Innovation Management, 19(2), 110-132.

Gatignon, H., Tushman, M.L., Smith, W., \& Anderson, P. (2002). A structural approach to assessing innovation: Construct development of innovation locus, type, and characteristics. Management Science, 48(9), 1103-1122.

Goldsmith, R.E., Freiden, J.B., \& Eastman, J.K. (1995). The generality/specificity issue in consumer innovativeness research. Technovation, 15(10), 601-612.

Goldsmith, R.E., \& Hofacker, C.F. (1991). Measuring consumer innovativeness. Journal of the Academy of Marketing Science, 19(3), 209-221.

Hägerstrand, T. (1967). Innovation diffusion as a spatial process. London: University of Chicago Press

Henderson, R.M., \& Clark, K.B. (1990). Architectural innovation-The reconfiguration of existing product technologies and the failure of established firms. Administrative Science Quarterly, 35(1), 9-30.

Henry, P.C. (2005). Social class, market situation, and consumers' metaphors of (dis)empowerment. Journal of Consumer Research, 31(4), 766-778.

Hirschman, E.C. (1980). Innovativeness, novelty seeking and consumer creativity. Journal of Consumer Research, 7(3), 283-295.

Homans, G.C. (1974). Social behaviour: Its elementary forms (Rev. ed.) New York: Harcourt Brace Jovanovich.

Im, S., Bayus, B.L., \& Mason, C.H. (2003). An empirical study of innate consumer innovativeness, personal characteristics, and new-product adoption behavior. Journal of the Academy of Marketing Science, 31(1), 61-73.

John, O.P., \& Srivastava, S. (1999). The big five trait taxonomy: History, measurement, and theoretical perspectives. In L.A. Pervin \& O.P. John (Eds.), Handbook of personality: Theory and research (2nd ed., pp. 102 138). London: Guilford Press.

Katz, E.P., \& Lazarsfeld, P.F. (1964). Personal influence. New York: Free Press.

Kaufman, R.J., \& Techatassanasoontorn, A.A. (2005). International diffusion of digital mobile technology: A coupled-hazard state-based approach Information Technology and Management, 6, 253-292.

Kirton, M.J. (1976). Adaptors and innovators: A description and measure. Journal of Applied Psychology, 61(5), 622-629.

Kirton, M.J. (1994). A theory of cognitive style. In M.J. Kirton (Ed.) Adopters and innovators: Styles of creativity and problem solving (Rev. ed.) (pp. 1-33). London: Routledge.

Kwang, N.A., \& Rodrigues, D. (2002). A big-five personality profile of the adaptor and innovator. Journal of Creative Behavior, 36(4), 254-268.

Larose, R., \& Atkin, D. (1988). Satisfaction, demographic, and media environment predictors of cable subscription. Journal of Broadcasting \& Electronic Media, 32(4), 403-413.

Larose, R., \& Atkin, D. (1992). Audiotext and the reinvention of the telephone as a mass medium. Journalism Quarterly, 69(2), 413-421.

Leung, L. (1998). Lifestyles and the use of new media technology in urban China. Telecommunications Policy, 22(9), 781-790.

Leung, L., \& Wei, R. (1999). Who are the mobile phone have-nots? New Media \& Society, 1(2), 209-226.

Mahler, A., \& Rogers, E.M. (1999). The diffusion of interactive communication innovations and the critical mass: The adoption of telecommunications services by German banks. Telecommunications Policy, 23(10-11) 719-740.

Mammes, I. (2004). Promoting girls' interest in technology through technology education: A research study. International Journal of Technology and Design Education, 14(2), 89-100.

McCrae, R.R., \& John, O.P. (1992). An introduction to the five-factor model and its applications. Journal of Personality, 60, 175-215.

McCullagh, P. (1980). Regression models for ordinal data. Journal of the Royal Statistical Society, 42(2), 109-142.

McCullagh, P., \& Nelder, J.A. (1998). Generalized linear models (2nd ed. Vol. 37). London: Chapman \& Hall.

Midgley, D.F., \& Dowling, G.R. (1978). Innovativeness: The concept and its measurement. Journal of Consumer Research, 4(4), 229-242.

Moss, M.L., \& Townsend, A.M. (2000). The Internet backbone and the American metropolis. Information Society, 16(1), 35-47. 
Mudd, S. (1990). The place of innovativeness in models of the adoption process-An integrative review. Technovation, 10(2), 119-136.

Podsakoff, P.M., MacKenzie, S.B., Lee, J.Y., \& Podsakoff, N.P. (2003). Common method biases in behavioral research: A critical review of the literature and recommended remedies. Journal of Applied Psychology, 88(5), 879-903.

R Development Core Team. (2007). R: A language and environment for statistical computing. Vienna, Austria: R Foundation for Statistical Computing.

Richerson, P.J., \& Boyd, R. (2005). Not by genes alone: How culture transformed human evolution. Chicago and London: University of Chicago Press.

Roehrich, G. (2004). Consumer innovativeness-Concepts and measurements. Journal of Business Research, 57(6), 671-677.

Rogers, E.M. (1983). Diffusion of innovations (3rd ed.). New York: Free Press.

Rogers, E.M. (2003). Diffusion of innovations (5th ed.). New York: Free Press.

Steenkamp, J.B.E.M., ter Hofstede, F., \& Wedel, M. (1999). A cross-national investigation into the individual and national cultural antecedents of consumer innovativeness. Journal of Marketing, 63(2), 55-69.

Summers, J.O. (1970). The identity of women's clothing fashion opinion leaders. Journal of Marketing Research, 7(2), 178-185.

Sung, N., \& Lee, Y.H. (2002). Substitution between mobile and fixed telephones in Korea. Review of Industrial Organization, 20(4), 367-374.

Tolnay, S.E. (1995). The spatial diffusion of fertility-A cross-sectional analysis of counties in the American South, 1940. American Sociological Review, 60(2), 299-308
Utterback, J.M. (1996). Mastering the dynamics of innovation. Boston: HBS Press.

Valente, T.W. (1995). Network models of the diffusion of innovations. Cresskill, NJ: Hampton Press.

Van den Bulte, C. (2000). New product diffusion acceleration: Measurement and analysis. Marketing Science, 19(4), 366-380.

Van Rijnsoever, F.J., \& Castaldi, C. (2009). Perceived technology clusters and ownership of related technologies: The case of consumer electronics. Journal of the American Society for Information Science and Technology, 60(2), 381-392.

Vishwanath, A. (2005). Impact of personality on technology adoption: An empirical model. Journal of the American Society for Information Science and Technology, 56(8), 803-811.

Vishwanath, A., \& Chen, H. (2006). Technology clusters: Using multidimensional scaling to evaluate and structure technology clusters. Journal of the American Society for Information Science and Technology, 57(11), 1451-1460.

Vishwanath, A., \& Goldhaber, G.M. (2003). An examination of the factors contributing to adoption decisions among late-diffused technology products. New Media \& Society, 5(4), 547-572.

Wejnert, B. (2002). Integrating models of diffusion of innovations: A conceptual framework. Annual Review of Sociology, 28, 297-326.

Yang, K.C.C. (2005). Exploring factors affecting the adoption of mobile commerce in Singapore. Telematics and Informatics, 22, 257-277.

Yukl, G., \& Van Fleet, D.D. (1992). Theory and research on leadership in organizations. In M.D. Dunnette \& L.M. Hough (Eds.), Handbook of industrial and organizational psychology (Vol. 3, pp. 147-197). Palo Alto, CA: Consulting Psychologists Press.

Appendix A. Perceived leadership and perceived trendiness scales.

\begin{tabular}{ll}
\hline & \multicolumn{1}{c}{ Items for perceived leadership $(\alpha=0.848)$} \\
\hline 1 & I am a natural leader. \\
2 & I am a natural chairman. \\
3 & Among others, I am often the most talkative. \\
4 & In discussions I often win. \\
5 & In a group I often take the initiative. \\
6 & I am charismatic. \\
7 & I aspire a function in which leading is a central part. \\
\hline & $\quad$ Items for perceived trendiness ( $\alpha=0.726)$. \\
\hline 1 & I always try to participate in the latest trends. \\
2 & I am fashionable. \\
3 & I always try keep in touch with the latest trends. \\
4 & I am always fast with buying new equipment. \\
5 & I think looks are very important. \\
\hline
\end{tabular}


Appendix B. Correlation matrix of the variables in Study 1.

\begin{tabular}{|c|c|c|c|c|c|c|c|c|c|c|c|c|c|c|}
\hline & $\begin{array}{l}\text { Domain- } \\
\text { specific } \\
\text { adoption }\end{array}$ & Product 1 & Product 2 & Product 3 & Product 4 & Product 5 & Product 6 & Product 7 & Product 8 & $\begin{array}{c}\text { Global } \\
\text { innovativeness }\end{array}$ & Leadership & Trendiness & Age & Sex \\
\hline \multicolumn{15}{|l|}{$\begin{array}{l}\text { Domain- } \\
\text { specific } \\
\text { adoption }\end{array}$} \\
\hline Product 1 & $.565^{* *}$ & & & & & & & & & & & & & \\
\hline Product 2 & $.318 * *$ & .062 & & & & & & & & & & & & \\
\hline Product 3 & $.468 * *$ & .138 & .158 & & & & & & & & & & & \\
\hline Product 4 & $.433 * *$ & $.174 *$ & -.157 & .054 & & & & & & & & & & \\
\hline Product 5 & $.544 * *$ & $.188^{*}$ & .084 & .061 & .107 & & & & & & & & & \\
\hline Product 6 & $.436 * *$ & .127 & .063 & .136 & .019 & $.257 * *$ & & & & & & & & \\
\hline Product 7 & $.380 * *$ & .133 & .020 & $-.180 *$ & .095 & .082 & $.225^{* *}$ & & & & & & & \\
\hline Product 8 & $.485^{* *}$ & .138 & .102 & $.319 * *$ & .102 & .122 & .023 & .018 & & & & & & \\
\hline $\begin{array}{l}\text { Global } \\
\text { innovativeness }\end{array}$ & .157 & .087 & .096 & .061 & -.004 & .159 & .006 & .047 & .108 & & & & & \\
\hline Leadership & .143 & $.179 *$ & .024 & .130 & -.048 & .123 & .036 & -.059 & .127 & $.325^{* *}$ & & & & \\
\hline Trendiness & $.433 * *$ & $.343 * *$ & $.232 * *$ & $.234 * *$ & .140 & $.196^{*}$ & $.216^{*}$ & .074 & .158 & -.063 & .166 & & & \\
\hline Age & $.168^{*}$ & .121 & -.053 & .027 & -.071 & $.170 *$ & .145 & $.169 *$ & .118 & $.213^{*}$ & .054 & .052 & & \\
\hline Sex & $-.228 * *$ & -.123 & -.058 & $-.262 * *$ & -.085 & -.063 & -.092 & .011 & -.158 & -.007 & .029 & -.102 & $-.215^{*}$ & \\
\hline
\end{tabular}

Note. $N=138$; all are Pearson correlations.

*Correlation significant at the .05 level (two-tailed).

**Correlation significant at the .01 level (two-tailed).

Appendix C. Correlation matrix of the variables in Study 2.

\begin{tabular}{|c|c|c|c|c|c|c|c|c|}
\hline & $\begin{array}{c}\text { Domain- } \\
\text { specific } \\
\text { innovativeness }\end{array}$ & $\begin{array}{c}\text { PC time of } \\
\text { adoption }\end{array}$ & $\begin{array}{l}\text { MP time of } \\
\text { adoption }\end{array}$ & $\begin{array}{l}\text { Internet time } \\
\text { of adoption }\end{array}$ & $\begin{array}{c}\text { Global } \\
\text { innovativeness }\end{array}$ & $\begin{array}{c}\text { Socioeconomic } \\
\text { level }\end{array}$ & $\begin{array}{c}\text { Socioeconomic } \\
\text { level }\end{array}$ & Age \\
\hline PC time of adoption & $.804 * *$ & & & & & & & \\
\hline MP time of adoption & $.664 * *$ & $.341 * *$ & & & & & & \\
\hline Internet time of adoption & $.686^{* *}$ & $.387 * *$ & .091 & & & & & \\
\hline Global innovativeness & $.127 * *$ & .072 & .065 & $.136^{* *}$ & & & & \\
\hline Socioeconomic level & $.356^{* *}$ & $.392 * *$ & $.237 * *$ & $.136^{* *}$ & -.026 & & & \\
\hline Place of residence & -.069 & -.076 & -.093 & .021 & .041 & -.029 & & \\
\hline Age & $.305 * *$ & $.410 * *$ & $.108 *$ & $.138^{* *}$ & -.058 & $.703 * *$ & -.015 & \\
\hline Sex & -.093 & -.036 & -.089 & -.076 & $-.193 * *$ & .035 & -.063 & $.121^{*}$ \\
\hline
\end{tabular}

Note. $N=450$.

*Correlation significant at the .05 level (two-tailed).

**Correlation significant at the .01 level (two-tailed). 